\title{
How The Web Radically Transforms Communication Networks
}

\author{
Thierry Pollet \\ Alcatel-Lucent \\ Copernicuslaan 50 \\ 2018 Antwerp, Belgium \\ +32479938310 \\ Thierry.Pollet@alcatel-lucent.be
}

\begin{abstract}
Web 2.0, has sparked a number of societal, business and technology changes. This transformation obviously is not restricted to the Internet domain but has influenced the enterprise and telecommunications space. This paper investigates the implications of the paradigm shift from the user-centric services environment to the community-centric, open services model. More in particular, it details how Web 2.0 has impacted the telecommunications space.
\end{abstract}

\section{Categories and Subject Descriptors C2.4 [Distributed Systems]}

\section{General Terms \\ Design}

\section{Keywords}

Web 2.0, Telco 2.0, Mashup, Web Services, SOA, Overlay Networks, Virtualization, Service Delivery Environment. IP Multimedia System (IMS), IP Television (IPTV).

\section{INTRODUCTION}

The Internet community is fueling services innovation, as on the Net creativity is bound only by the imagination of an evergrowing online community. The term Web 2.0 has been coined during a fertile thought leadership exercise at the occasion of the Friends of O'Reilly Camp in 2004 [1]. One of fundamental principles in Web 2.0 is that role between consumer and producer is no longer strictly segregated and consumers increasingly become involved into production of content and creation of services. In particular, the example of YouTube is a proof point for success of user-generated video content. The power of the community is a second pillar. This includes community-based knowledge generation under form of online encyclopedias, blogs as well as the open-source software movement. These are illustrations of the paradigm shift from the user-centric consumption model towards a community-centric collaborative model. This paper investigates how these changes impact the telecommunications environment. In section 1 , an overview is given of the current telecommunications environment. Section 2 highlights the expected influences from the Web 2.0 wave.

Permission to make digital or hard copies of all or part of this work for personal or classroom use is granted without fee provided that copies are not made or distributed for profit or commercial advantage and that copies bear this notice and the full citation on the first page. To copy otherwise, to republish, to post on servers or to redistribute to lists, requires prior specific permission and/or a fee.

AUTONOMICS 2007, 28-30 October 2007, Rome, Italy

Copyright $\odot 2007$ ICST 978-963-9799-09-7

DOI 10.4108/ICST.AUTONOMICS2007.2402

\section{THE TELCO ENVIRONMENT}

Figure 1 depicts the current telecommunications environment with a focus on the services layer. Historically, service providers have built an environment of application-optimized service platforms. Their current focus is to break down these service silos to extract greater value from their resources and satisfy customer demand for context-aware, blended and personalized multidomain services. This new service delivery environment (SDE) often adheres to service oriented architecture (SOA) principles: an architecture that uses loosely coupled services to support the requirements of business processes and users. Resources in a SOA environment are available as independent services (i.e., they can be accessed without knowledge of their underlying service delivery platform (SDP) on which they are deployed). Each individual SDP generally is composed of application platforms, service enablers and control elements dedicated to that service's delivery domain. The following domains can be distinguished: IMS for delivery of session-centric conversational, video and messaging services, IPTV for multi-media delivery, mobile services, legacy Intelligent Networks (IN) and Web. The service factory is the environment in which to create personalized Xdomain (blended) services.

\section{HOW WEB 2.0 CHANGES THE TELCO}

\subsection{The Business Environment}

Where the telco has in it's historical role positioned itself in the waist of the hour-glass for service delivery, controlling its business partners in delivering services to the end-users, in Web 2.0 , a business can be operated in such a way that business sub processes that are not part of the core value proposition are outsourced to third party Web Service providers. Examples of these providers are Salesforce for customer relation management, Amazon for e-commerce, Paypal for payment, etc. The unique value proposition of the business on one hand, and outsourced processes on the other hand are tied together through a workflow. This Web 2.0 environment eliminates a number of essential barriers hindering ventures to become successful: it offers a platform - readily available, that allows a new business to get to operate, grow and scale with global reach. This is in particular relevant for small initiatives that otherwise would have been faced with insuperable large infrastructure and software investments. It is the challenge to the telco to reinvent itself to fit into this new model: as any other player, it has to expose assets as a "Software as a Service" (SaaS) the business eco-system. The questions that remain to be answered are: what are these differentiating services, and how can profitable business be generated with them? It is 


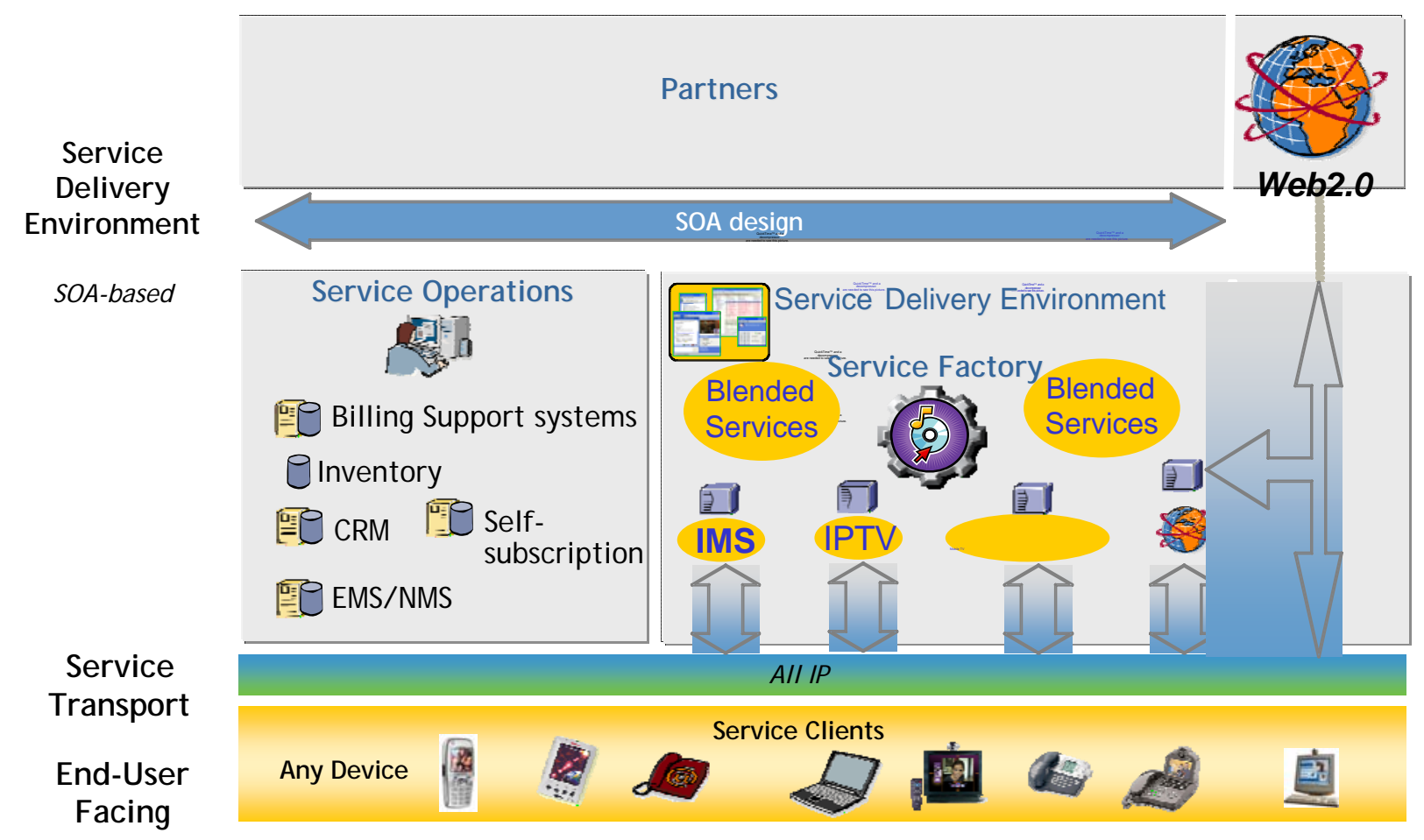

Figure 1: Current Telco Service Delivery Environment

clear that the operator's effort to integrate the Web 2.0 with its existing application domains through the service factory is just a first step. Examples are: merging Web and IMS address books, buddy lists and presence; seamless transfer of streamed Web content to IPTV and IMS terminals; telco presence and location enriched web sites. Currently, telco's are exploring alternative business models that have proven their value on the Internet: offer basic communication services for free and feed the top line through $3^{\text {rd }}$ party revenues (for instance through personalized advertising) and premium services. This obviously requires operators to re-engineer their business layer and build new value networks.

\subsection{Society: Consumption \& Production}

The immense popular YouTube is not the only platform to host user generated videos. Advanced IPTV systems allow the enduser to upload his content to so called "virtual channels" that can be viewed by communities or the public on demand or in carrousel mode. Whereas these systems offer advanced access control and attractive rights conditions they are currently limited to the geographic reach of the IPTV operator.

Community TV provides the user with the experience of watching television with remote community members as if everyone were in the same room. By enhancing broadcast TV with communication within a community, this creates a rich social experience. This service enhances broadcast IPTV service is built upon the following features:

- Group voice chat with friends or family members watching the same TV broadcast event
- A buddy mosaic showing which TV channel your friends are presently watching

- $\quad$ Personalized avatars, representing you and your friends on the TV screen

- Multimedia emoticons, which are audio-visual messages sent to your friends' TV screen, expressing your emotions

Similar as on the Internet, operators offer services to manage your personal content, and when desired so, to share this within a community. Moreover, the content can be accessed irrespective of the type of end-terminal (mobile, PC) or where the source data has been stored. The network has the intelligence to store, replicate or cash the data to ensure fast access irrespective the characteristics of the network connected to (broadband or narrowband).

Bottom line is, that the societal needs stirred by the innovation on the Internet, are also being addressed by the operator.

\subsection{Technology: Services \& Networks}

Along with Web 2.0, a new paradigm came for service development on the Internet. The arrival of Web Services (WS) to the ICT scene revolutionized the software architecture in the public Internet space but also in the enterprise sector. On the Internet, the movement for open API's advanced even further. Relying on the basic WS infrastructure, XML over HTTP, a lighter version of the WS paradigm captures popularity. REST and POX (Plain Old XML) interfaces to data-rich services created the opportunity to use common web servers and Internet browsers as a platform to create arbitrary but meaningful data mixes. Those combinations, called "Mashups" are truly synergetic 
constructions, as the service offered by the mashup is greater than the simple addition of the participating components. Whereas in their initial form these new kind of applications were rather naive and amusing in nature, the concept is maturing and fast finding its reduce network transport cost. Both P2P and CDN technology, albeit in modified form, is adopted by the operator to deliver its services (e.g. IPTV).

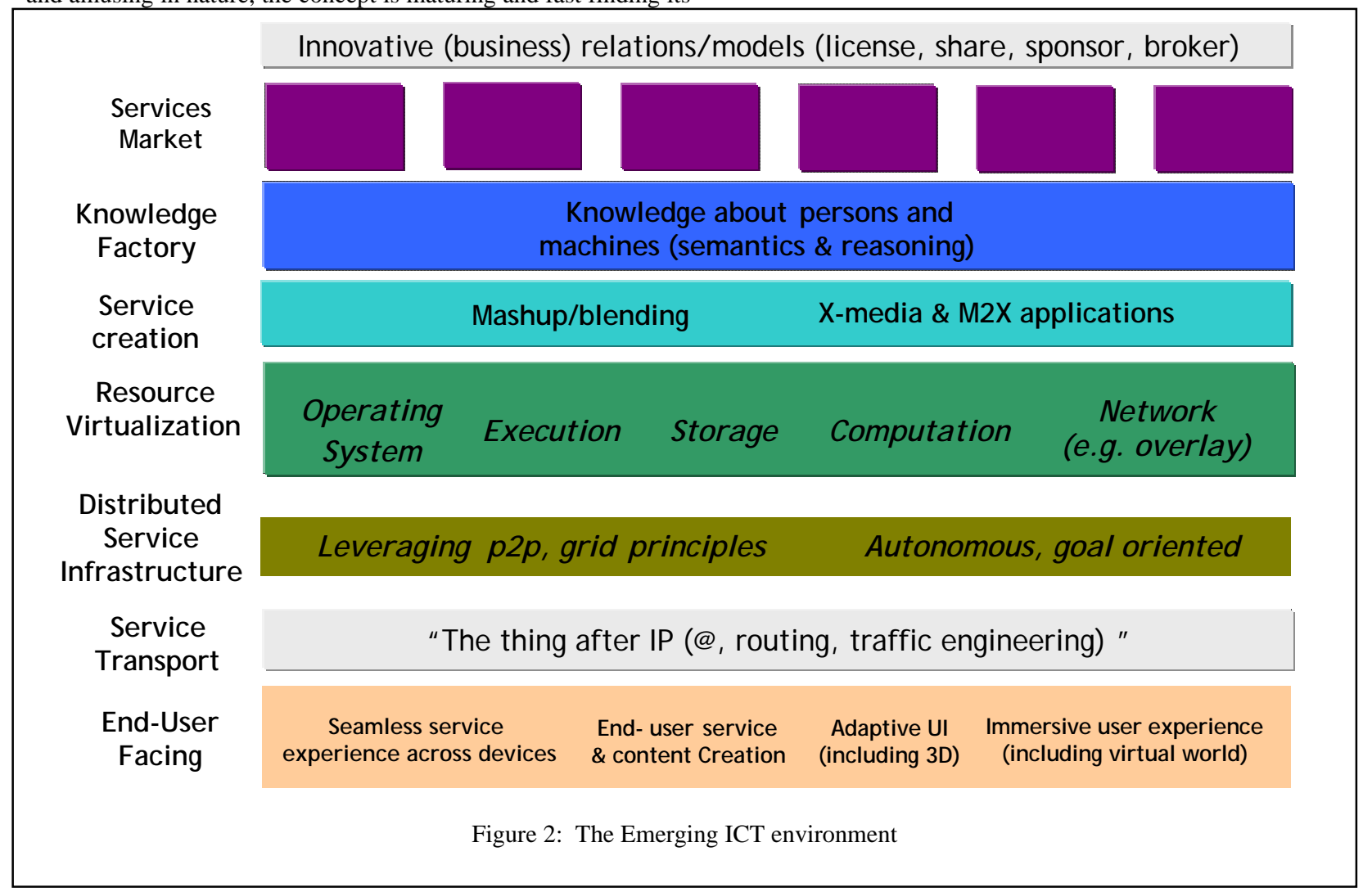

way into the enterprise and the Telco domain. Web21C, the BT communications API, which allows developers to easily add communication functions to their mashups is a good example.

Mashups promise a short cycle for service development relying on reuse of existent Web services and software, useable by domain experts or even end-users rather than IT experts. The underpinning technologies are: RSS, ATOM, AJAX, JSON, REST, SOAP. Telco2.0 mashups primarily focuses on fast and easy development of communication and multi-media services assembled from telco exposed assets such as: click-to-dial, geolocation and presence services, SMS services etc..

Internet services are delivered over an IP pipe with little knowledge or control over the underlying transport network. This limitation is in particular harmful when delivering bandwidthhungry services such as video, highly scaleable distributed services such as voice and messaging. Peer-to-peer (P2P) and content distribution networks (CDN) are overlay architectures that have been introduced to overcome (in part) these limitations. P2P technology, originally used for distributed file storage and retrieval, is now being adopted for voice and messaging services and Internet video. By nature, P2P has the attractive property that the infrastructure pool automatically grows as the service takes up and little investment is required to bootstrap the service. CDN 's are essential for offloading frequent accessed Web servers reducing service access delay within bounds unnoticeable to the end-user. In addition, proper caching techniques can largely

\section{Conclusion}

The x2.0 wave has fueled innovation in various domains: from tools, programming models, creation and deployment platforms as well as key service enablers to market places. But more importantly, it has fundamentally changed how end-users deal with services and how businesses are run. With Web2.0 around for a few years now, Web 3.0 is glimpsing around the corner. Its scope is currently under definition - following characteristics are attributed to x3.0: semantics, reasoning, 3D and virtual environments, autonomous operation and truly distributed data repositories. Most likely, as its predecessor, Web3.0 will race as a whirlwind through the ICT landscape. The outlook my turn out to be as in Figure 2.

\section{ACKNOWLEDGMENTS}

The author gratefully acknowledges Markus Hofmann and Gerard Maas, both with the research organization of Alcatel-Lucent, for their contribution to this paper.

\section{REFERENCES}

[1] Friedman, F., 2006, The World is Flat, Penguin Books, ISBN_13, 978_0_141_03489_8. 